\title{
Trichoderma species as Biocontrol Agent against Soil Borne Fungal Pathogens
}

\author{
Srijana Bastakoti ${ }^{*}$, Shiva Belbase ${ }^{1}$, Shrinkhala Manandhar ${ }^{2}$, Charu Arjyal $^{1}$ \\ ${ }^{1}$ Department of Microbiology, Tri-Chandra Multiple Campus, Ghantaghar, Kathmandu, Nepal \\ 2Plant Pathology Laboratory, Nepal Agricultural Research Council (NARC), Khumaltar, \\ Lalitpur, Nepal
}

\begin{abstract}
Soil borne pathogenic fungi are of major concern in agriculture which significantly decreases the plant yield. Chemically controlled plant imposes environmental threats potentially dangerous to humans as well as other animals. Thus, application of biological methods in plant disease control is more effective alternative technique. This study was carried out to isolate Trichoderma species from soil sample and to assess its in vitro biocontrol efficacy against fungal pathogens viz. Sclerotium rolfsii, Sclerotionia sclerotiorum, Fusarium solani and Rhizoctonia solani. Biocontrol efficacy testing of isolates against different fungal pathogens was performed by dual culture technique.

In this study, five different Trichoderma species were isolated from 26 various soil samples and were tested against four fungal soil-borne pathogens. Inhibition percentage of radial growth of Sclerotium rolfsii by three of the Trichoderma isolates was found to be $100 \%$; about $62 \%$ and $68 \%$ of maximum inhibition was observed against Rhizoctonia solani and Fusarium solani respectively whereas Sclerotionia sclerotiorum was inhibited maximum up to $23 \%$. This in vitro study revealed that although Trichoderma species plays an important role in controlling all type of soil borne fungal plant pathogens, however, isolates as biocontrol agent against Sclerotium rolfsii was found to be more efficient in comparison to other pathogens.
\end{abstract}

Keywords: Biocontrol, Trichoderma species, inhibition percentage, soil borne pathogens and dual culture technique

*Correspondence Author

Email: srijanabastakoti33@gmail.com

\section{Introduction}

Soil borne plant pathogenic fungi cause heavy crop losses all over the world. Agriculture has been facing the destructive activities of numerous pests and pathogens from an early time, which leads not only to the reduction of yield of the crops but also the aesthetic value. Chemical control of such plant pathogens disturbs the environment, subverts ecology, degrades soil productivity, and mismanages water resources [1, 2]. In addition to this, due to the growing cost of pesticides, particularly in the less affluent region of the world and consumer demands for pesticide-free food has led to the search for the substitutes for these products. Biological control of plant diseases, especially those caused by soil borne plant pathogens and nematodes, by microorganisms has been considered a more natural and environmentally acceptable alternative to the existing chemical treatment methods [3]. The renewed interest in biocontrol among agriculture biologists is due to its eco-friendly protection against weeds, insects, and plant diseases, a long lasting effect, and safety features. Some of the bacterial antagonists, however, also have been found to show direct growth promoting effects on crop plant inoculants [4,5].

Biocontrol agent (BCAs) can inhibit the growth of soil borne pathogens through various biocontrol mechanisms such as ability to grow much faster than them for space and nutrients, producing many powerful plant degrading enzymes such as lytic enzymes, proteolytic enzymes and more than 200 types of antibiotics which are highly toxic to any macro- and microorganism [6]. The ability to produce multiple antibiotics probably helps to suppress diverse microbial competitors, some of which are likely to be plant pathogens and thus enhance biological control. The antibiotics have been shown to be particularly effective at suppressing growth of the target pathogen in vitro and/or in situ. Some examples of antibiotics reported to be involved in plant pathogen suppression are 2, 4-diacetylphloroglucinol produced by Pseudomonas fluorescens F113 against Pythium species which causes the damping off disease, gliotoxin produced by Trichoderma virens against Rhizoctonia solani which causes root rot in plants [7]. Moreover, enzymes produced by BCAs are able to hydrolyze chitin, proteins, cellulose, and hemicellulose.

Thus contributing to direct suppression of plant pathogens. There are selective examples of BCAs able to produce enzymes effective against certain plant pathogens [8].

Plant disease is a complex phenomenon and, is an interaction among the host, the parasite and the environment. It can be defined as the disturbance in the 
rhythmical equilibrium of a host in respect of structure or physiology or both, and which may lead to the death of a part or entire host or reduce value of its products. The mycelium of Sclerotium rolfsii survives best in sandy soils, whereas, the sclerotia survive best in moist, aerobic conditions found at the soil surface [9]. Similarly, Fusarium solani and Rhizoctonia solani are the most important fungal pathogens, which develop in both cultured and non-cultured soils, causing the symptoms of damping off and root rot diseases to the wide range of vegetable and crop plants including tomato [10]. For the effective biocontrol of soil borne pathogens a major consideration is the antagonist's proliferation after introduction into the soil.

Trichoderma species is considered as promising biological control agents against numerous phytopathogenic fungi since it is able to inhibit the phytopathogenic fungi either by including resistance and plant defense reaction or by direct confrontation through mycoparasitism and competition or by producing antibiotics [11]. Trichoderma species not only produce potential antibiotics, for example the peptaibols, but also mycotoxins and more than 100 metabolites with antibiotic activities including polyketides, pyrones, terpenes, metabolites derived from amino acids and polypeptides [12]. Trichoderma species being a biocontrol agent have shown efficacy against diseases caused by pathogens such as Fusarium oxysporum, Rhizoctonia solani, Pythium aphanidermatium, Fusarium culmorum, Gaeumannomyces graminis var. tritici, Sclerotium rolfsii, Phytophthora cactorum, Botrytis cinerea and Alternaria species [13]. Thus, Trichoderma species has been considered a viable alternative method to manage plant diseases [14]. The role of Trichoderma species is not only to control the growth of pathogenic microbes, but there are various other uses for Trichoderma species such as, enhance plant defense responses, stimulate colonization of rhizosphere and stimulates plant growth, root growth $[15,16]$.

\section{Materials and Methodology}

\section{Collection of soil sample}

Twenty-six soil samples were collected from different geographical region of Nepal: Himalayan region, Hilly region and Terai region. Both fresh and decaying soil samples from old and new heaps were collected into clean polythene bags cultivated with crops like cauliflower, potato, orange, wheat, pea, mustard, coffee, carrot, garlic, banana and tomato.Some of the Trichoderma isolate were obtained from the soil of hilly region (Kathmandu, Lalitpur, Nuwakot) cultivated with oranges, pea wheat, cauliflower, potato. Similarly, soil sample collected from terai region (Sarlahi, Siraha, Bardiya) having warm and humid climate was cultivated with mustard, broad bean, eggplant representing growth of some Trichoderma isolates. Jumla, having warm and temperate climate was also one of the spot for the collection of soil sample. Primarily, soil samples were collected from the zone which has used only organic fertilizer and has not used any pesticides, fungicides or any other chemical agent, to know natural availability of biocontrol agent. It is because, biocontrol agents are not much available in such agricultural land with excessive use of chemical fertilizers since it leads to the inhibition of biocontrol agents present in that soil.

\section{Isolation of biocontrol agent, Trichoderma species}

The collected soil sample from different geographical regions of Nepal was used for isolation of Trichoderma species. From the serial dilution, soil samples of $0.5 \mathrm{ml}$ each was poured in selective media Potato Dextrose Agar (PDA) for isolation of Trichoderma species and soil plating were performed. The plate was then allowed to incubate for $3-4$ days at $25-26^{\circ} \mathrm{C}$. Incubation results the fuzzy growth of fungus on the PDA plate was observed which was also seen after seven days of cultivation.

\section{Identification of Trichoderma isolates}

After the isolation of all isolates, it was examined under a microscope (Olympus $\mathrm{CH} 20$, at Plant Pathology Laboratory, NARC, Khumaltar, Lalitpur) for the identification and confirmatory of Trichoderma species. Macroscopic visualization showed rapid growth rate and colonies are wooly becoming compact in time; and the surface colony color was white and scattered greenish patches become visible as the conidia are formed and may form concentric rings at times while on the reverse, the color is pale, tan, or yellowish. After then, growth observed in those plates was taken for microscopic study, colony characteristics and morphology of each Trichoderma isolate was observed. Microscopic observation of specimens was done by the sticky tape method [17]. Examination of the shape, size, arrangement and development of conidiophores (repeatedly branched conidiophores) or phialides (irregularly verticillate, bearing clusters of divergent, often irregularly bent, flask - shaped phialides) or conidia (unicellular, round or ellipsoidal, green in color, smooth walled or rough conidia) provided a tentative identification of Trichoderma species. 


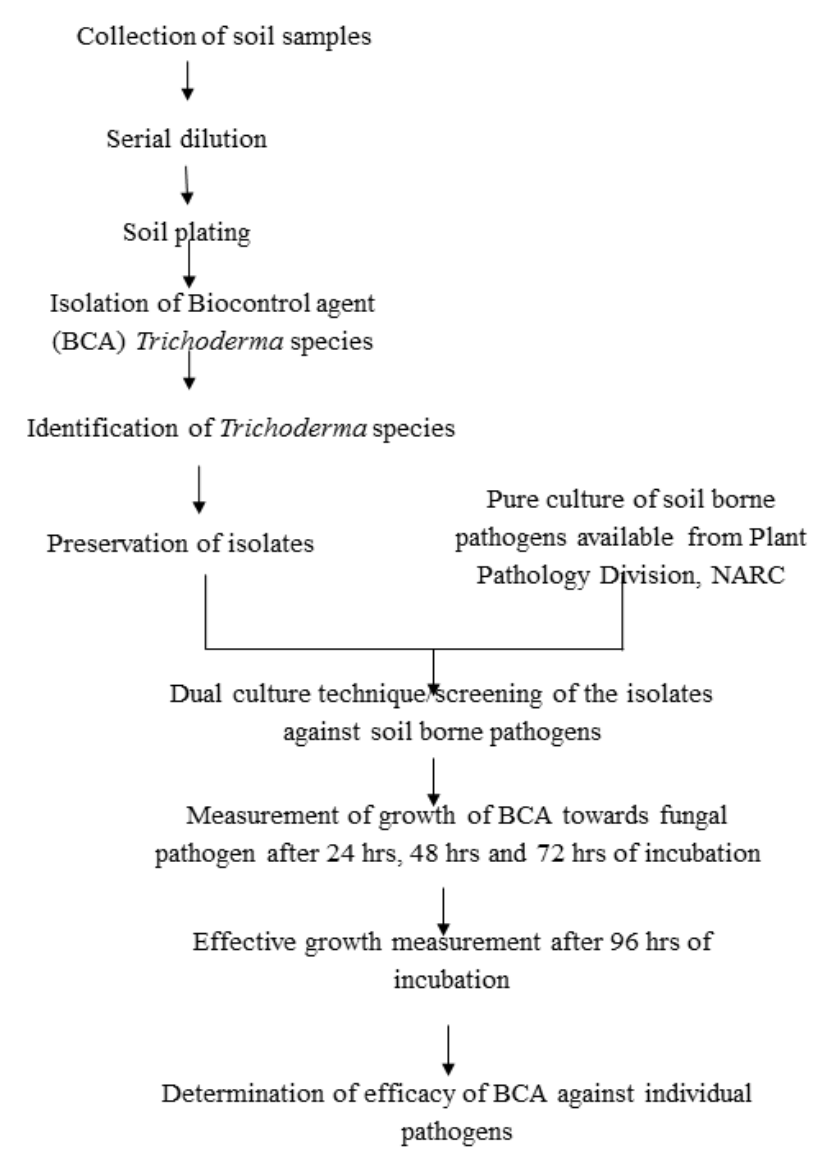

Figure 1: An overview of overall methodology

\section{Dual culture of isolates with fungal pathogens}

All the isolates obtained from the soil sample were evaluated in vitro for their biocontrol efficacy against fungal pathogens by dual culture methods. The soil borne fungal pathogens Sclerotium rolfsii, Rhizoctonia solani, Fusarium solani and Sclerotionia sclerotiorum were provided from the Plant Pathology lab of Nepal Agricultural Research Council (NARC) at Khumaltar, Lalitpur, Nepal. These fungal pathogens were isolated from naturally infected tomato, egg-plant, mustard plant and brassicas respectively causing wilt and rot disease and obtained in pure culture form.

First of all, $20 \mathrm{ml}$ of prepared PDA was poured in petri plates and allowed to solidify. After solidification of PDA media, $5 \mathrm{~mm}$ diameter mycelia disc from the margin of 7 day-old culture of Trichoderma species and the soil-borne pathogens were placed on the opposite ends of the plate at equal distance from the periphery on the same day. There were 3 replications for each treatment. The experimental design used was set up with eight Petri dishes for each isolate. In control plates, a sterile disc, Whatman No.1 filter paper of $5 \mathrm{~mm}$ diameter, was placed at opposite side of targeted fungal pathogens. The experiment was performed in complete aseptic condition and both the control plates and test plates were incubated at $25 \pm 1^{\circ} \mathrm{C}$ for 7 days. The colony diameter of radial growth of targeted fungal pathogens was measured after each $1^{\text {st }}, 2^{\text {nd }}, 3^{\text {rd }}$ and $4^{\text {th }}$ days of incubation period at two locations from center of the test placed and average diameter were calculated. Finally, percent inhibition of average radial growth was also calculated in relation to the growth of the controls [18] and the flowchart for methodology for this experiment is shown in Figure 1.

$\mathrm{L}=[(\mathrm{C}-\mathrm{T}) / \mathrm{C}] \times 100$

Where,

$\mathrm{L}=$ inhibition percentage;

$\mathrm{C}=$ radial growth measurement of the pathogen in control

$\mathrm{T}=$ radial growth of pathogen in the presence of Trichoderma isolates.

\section{Results \\ Isolation of biocontrol agent and microscopic view}

The growth of Trichoderma species in PDA plates were observed after 7 days of inoculation and incubation of soil samples. Isolated Trichoderma species from soil samples used as biocontrol agents is represented in Figure 2.

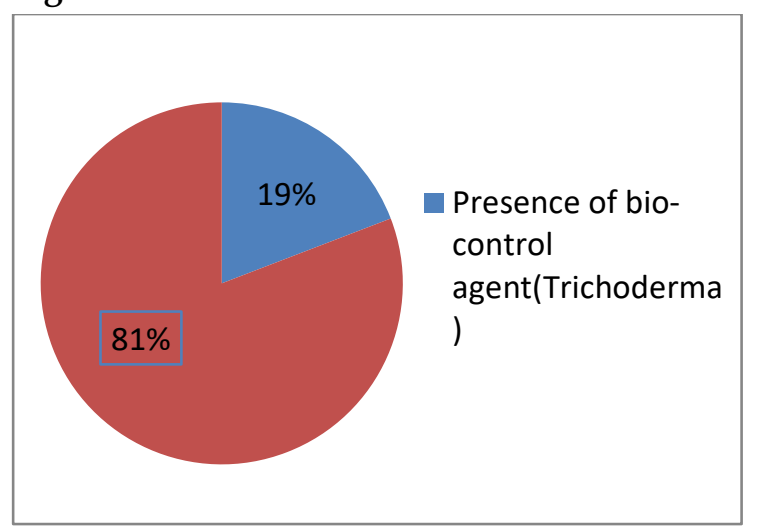

Figure: 2 Isolation of Trichoderma species from collected soil samples

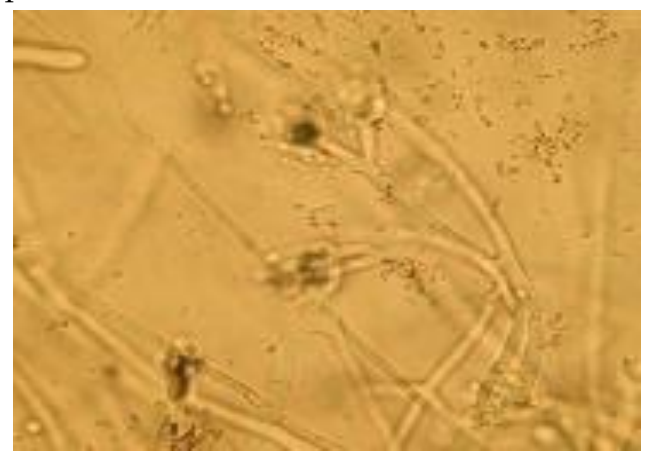

Figure 3: Microscopic view of Trichoderma isolate TS 206 with repeatedly branched Conidiophore, flask - shaped phialides and rough conidia 
Out of 26 soil samples tested, the Trichoderma species were isolated in 5 soil samples. The green or white colored fuzzy form growth indicated the Trichoderma species and was confirmed by the microscopic examination as shown in Figure 3.

\section{Inhibition percentage shown by Trichoderma isolates against soil borne pathogens}

Inhibition percentage of the test soil-borne pathogens in the presence of Trichoderma species was performed by dual culture technique which requires both the control plates and test plates. One of the control plates of Sclerotium rolfsii is shown in Figure 4 indicating three replications.

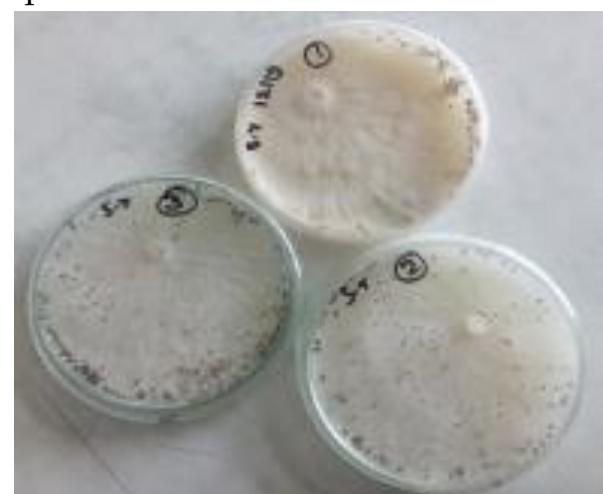

Figure 4: Colony growth in control plates of Sclerotium rolfsii after $96 \mathrm{hrs}$ of incubation shows the whole area of a petri plate is rapidly covered with mycelium, including aerial hyphae which may cover the lid of the plate

Among the test pathogens, Trichoderma isolates named as TS 209, TS 206 and TS 181 showed almost 100\% inhibitions against Sclerotium rolfsii by covering the growth of whole pathogen in the plate. Also, the isolates TS 214 after five day of incubation was found to work more actively against Sclerotium rolfsii as shown in Figure 5.

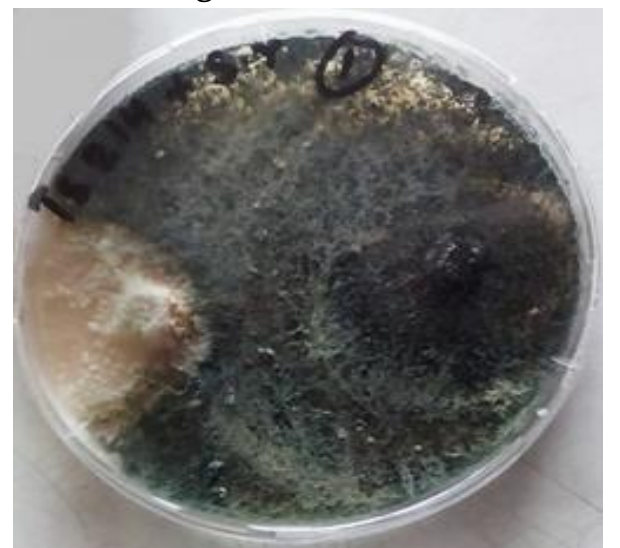

Figure 5: Dual culture plate of Sclerotium rolfsii with Trichoderma species after 5 th day of incubation shows a very well inhibition of white spores like mycelium of $S$. rolfsii by TS 214 isolates representing effective biological action over pathogens.
But the Sclerotionia sclerotiorum was not much controlled by Trichoderma isolate TS 215 indicating inhibition percentage of $22.01 \%$. Dual culture plate of Trichoderma isolates against Sclerotionia sclerotiorum is as shown in Figure 6. In the case of dual culture with Fusarium solani, one of the isolates of Trichoderma species showed the maximum inhibition percentage of $63.3 \%$ whereas, rest of the four isolates showed inhibition below 45\%. Similarly, isolates against Rhizoctonia solani also revealed growth inhibition of pathogens.

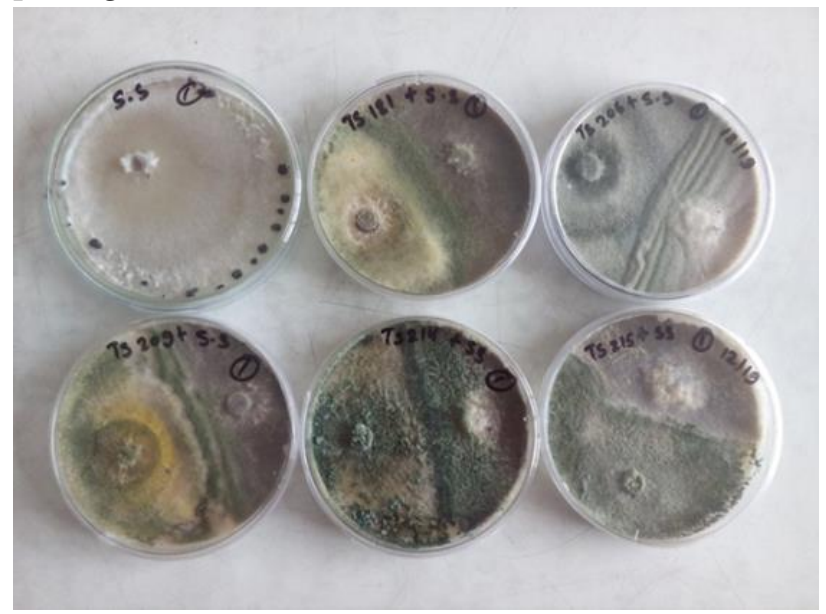

Figure 6: Dual culture plate of 5 different Trichoderma isolates against Sclerotionia sclerotiorum (S.S. 1 indicating first replication) after 96 hours of incubation shows competitive effect with almost equal mode of action over each other.

The maximum inhibition percentage observed was $66.08 \%$ which indicated effective reduction of the colony growth of Rhizoctonia solani after 96 hours cultivation. Other three isolates were also able to inhibit growth of Rhizoctonia solani pathogen up to $55.7 \%$, $47.2 \%, 43.77 \%$ and lowest inhibition percentage of 29.7\% was shown by one of Trichoderma species.

Therefore, among these test pathogens, Trichoderma species showed strong and effective biocontrol activity against Sclerotium rolfsii. The in vitro study also showed that Trichoderma species effectively reduced the growth of both Fusarium solani and Rhizoctonia solani with almost equal inhibition percentage.

Inhibition percentage of the test soil-borne pathogens in the presence of Trichoderma species by dual culture technique is shown in Figure 7.

\section{Discussion}

In this study, the results of dual culture revealed the rapid and effective growth of Trichoderma isolates used against Sclerotium rolfsii in comparison to other pathogens (Sclerotionia sclerotiorum, Fusarium solani and Rhizoctonia solani). 


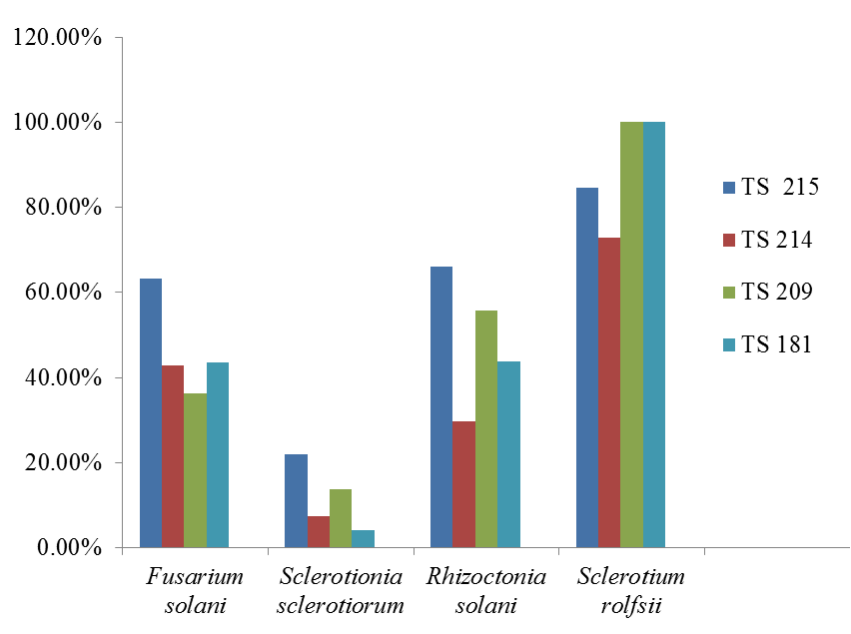

Figure 7: Inhibition percentage of all four soil borne fungal pathogens by five Trichoderma isolates shows individual biocontrol action of isolates over placed pathogens.

In vitro efficacy testing of biocontrol agent against soil borne pathogen was studied by dual culture technique. Three replication of Trichoderma species were used during this technique for the calculation of average diameter growth of respective pathogens for a reliable result. The colony growth of Sclerotium rolfsii on the $4^{\text {th }}$ day incubation was found to be covered by the growth of Trichoderma species. Due to overgrowth of Trichoderma species in the plate, the growth of test fungal pathogen was found to be highly inhibited. Antagonistic interactions of Trichoderma species isolate TS 215 showed excellent activity against Sclerotium rolfsii, which is known to cause wilt and rot diseases in plants. The damping off disease caused by Sclerotium rolfsiiis an important disease of tomato (Lycopersicon esculentum) and other vegetable crops when treated with biocontrol agent Trichoderma harzianum, about 52$62 \%$ disease reduction was achieved in another study [19]. Whereas, in this study, Sclerotium rolfsii isolated from infected tomato was found to be inhibited nearly up to $100 \%$ by three isolates of the Trichoderma species and two isolates showed inhibition of $84.5 \%$ and $72.8 \%$ respectively. Similarly, this study showed the mycelium growth inhibition of the Rhizoctonia solani of $66.08-29.07 \%$ by isolates of Trichoderma whereas in another study, three different isolates of Trichoderma against soil borne pathogen Rhizoctonia solani was observed to be 74.4-67.8\% [20]. However, some of the antagonists tested were not found to be very effective against test pathogens under the in vitro observations but they may show better result under their natural field condition as their activities depend on the physico- of the environment [21].

On the dual culture plate of Trichoderma species with Sclerotioni asclerotiorum, competitive effect was observed. Here pathogen continued its radial growth and Trichoderma species placed in the same plate also showed radial growth. When colony growth of pathogen and biocontrol agent came in contact with each other, both showed its action over each other, however, Trichoderma isolates was able to shown less efficacy over growth of pathogens.

In this study, biocontrol activity of Trichoderma isolate TS 215 also showed active action against soil borne pathogen Fusarium solani showing inhibition percentage more than $60 \%$. Similarly, from other experiment, under in vitro conditions, the result revealed that Trichoderma harzianum, isolates N-8, was found to inhibit the radial mycelial growth of the pathogen effectively by $68.22 \%$ [22]. The inhibition shown by the antagonists may be due to release of antibiotic or antibiotic like substances or hyphal parasitism which results in direct inhibition of growth of the pathogen by disintegrating the hyphal wall resulting in the penetration, absorption and lysis of the mycelium.

Biological control is a promising tool to maintain current level of agricultural production by reducing the release of polluting chemical pesticides to the environment as well as making the plants free from infecting soil borne pathogens, leading to high yield of crops. It is a complex process made up from several successive steps but primarily contact is made between fungal antagonist and host (pathogen) surface. Plant pathogenic fungi and nematodes is a widespread problem and the use of chemicals is hardly successful. According to this study, biological control is seen as a better alternative and may be helpful, especially against soil borne fungal pathogens Sclerotium rolfsii, Fusarium solani, Rhizoctonia solani and Sclerotioni asclerotiorum. One of the main advantages of the biocontrol agents is that it is cost effective and leads no harm to the crop.

Most frequently species of Bacillus, Pseudomonas and Trichoderma are used for biological control of fungal pathogens. Among them, one of the fungal biocontrol agents used in this study is Trichoderma species. They are common saprophytic fungi found in almost any soil and rhizospheric microflora. The reason for choosing Trichoderma species as potential biocontrol agents is because of their ability to reduce the incidence of disease caused by plant pathogenic fungi [23]. Possible mechanisms of antagonism employed by Trichoderma species includes nutrient and niche competitions, antibiosis by producing volatile components and non-volatile antibiotics that are inhibitory against a 
range of soil borne fungi, as well as parasitism. Antagonistic microorganisms like Trichoderma reduce growth, survival or infections caused by the pathogens by different mechanisms like competition, antibiosis, mycoparasitism, hyphal interactions, and enzyme secretion [24].

It is widely known that environmental parameters such as abiotic (soil type, soil temperature, soil $\mathrm{pH}$ and water potential) and biotic (plant species and variety, microbial activity of the soil) factors as well as other factors such as method and timing of applications may have influence on the biological control efficacy of Trichoderma isolates [25].The soil samples were collected from different districts that include hot region as well as cold region. The soil samples of cold region comparatively showed slow growth rate than that of hot region. Initially, in the PDA plates Trichoderma species is found to grow slowly, it may be due to the presence of other pathogens which have capacity to dominate or slow down the growth of Trichoderma species. It may also be due to dispersal of spores in the environment. This can be the reason why some Trichoderma species took almost one month for isolation.

The in vitro screening of the antagonistic potential used in this work allowed a systematic investigation of several Trichoderma isolates. The applied Trichoderma species in this study revealed the most effective inhibition of growth of fungal pathogen Sclerotium rolfsii and biocontrol action over rest of the test pathogens was limited. However, positive results obtained from this in vitro studies are only indicative, as experimental conditions do not take all ecological and endemic factors into account. For this reason, much more work needs to be done to explore the possibility of the use of this biocontrol agent in field condition to control the diseases caused by Sclerotium rolfsii and several other soil borne fungal pathogens by adopting appropriate techniques for field trial. Further actions need to be carried out to prepare cost-effective, easy-toproduce and easy-to-apply formulations of different species of Trichoderma isolates.

\section{CONCLUSION}

It can be concluded that the isolated Trichoderma species reduced the growth of all the four soil borne pathogens: Sclerotium rolfsii, Fusarium solani, Rhizoctonia solani and Sclerotionia sclerotiorum significantly in different level and, therefore, can be incorporated for integrated disease management of soil borne plant pathogens. Hence, Trichoderma species can be used as a potential biocontrol agent against these pathogens. However, its efficacy against Sclerotium rolfsii was found to be more in comparison to others. Therefore, this research can have promising potential in agricultural field to protect plants affected with various fungal pathogens, especially Sclerotium rolfsii.

\section{ACKNOWLEDGEMENT}

We would like to extend our gratitude to Dr. Baidya Nath Mahato, Chief and Principal Scientist of Plant Pathology Division, Nepal Agricultural Research Council (NARC) for providing us an opportunity to conduct this study, Puspa Shrestha for providing guidance during the experiments at Plant Pathology laboratory and all the staffs for their support. We are also grateful to the teachers and staffs of Department of Microbiology, Tri-Chandra Multiple Campus for their support in completing this task.

\section{Conflict of interest}

None

\section{References}

1. Ayala S and RaoEVSP: Perspective of soil fertility management with a focus on fertilizer use for crop productivity. CurrSci. 2002 82: 797-807.

2. Deshwal VK, Dubey RC and Maheshwari DK: Isolation of plant growth promoting strains of Bradyrhizobium Arachis sp. with biocontrol potential against Macrophomina phaseolina causing charcoal rot of peanut. CurrSci. 2003a 84(3): 443-448.

3. Gerhardson B: Biological substitute for pesticides. Trends Biotechnology. 2002 20: 338-343.

4. Barker $\mathrm{R}$ and Paulitz TC: Theoretical basis for microbial interactions leading to biological control of soil borne plant pathogens In: Hall $\mathbf{R}$ (Ed). Principal and practice of managing soil borne plant pathogen. Am. Phythopathol. Soc. St. Paul Mn. 1996 50-79.

5. Deshwal VK, Pandey P, Kang SC and Maheshwari DK:Rhizobia as a biological control agent against soil borne plant pathogenic fungi. Ind J ExpBiol. 2003b 41: 1160-1164.

6. Kubicek CP and Harman GE: Trichoderma and Gliocladium. Basic Biology, Taxonomy and Genetics. Volume 1. Taylor and Francis; London 1998: 139-191.

7. Pal and McSpadden: Biological Control of Plant Pathogens. The Plant Health Instructor. DOI: 10.1094/PHI-a-2006-1117-02.

8. Ningaraju TM: Cloning and characterization of chitinase gene/s from native isolates of Serratia 
marcescens. Msc. Thesis UAS Dharwad 2006 pp 3340.

9. Arunasri P, Chalam TV, Eswara Reddy NP, Tirumala Reddy S: Collar-rot disease of crossandra induced by Sclerotium rolfsii and its management. A critical review (International Journal of Applied Biology and Pharmaceutical Technology) 2011 306-314.

10. Abu-Taleb, M. Amira, Kadriya El-Deeb and Fatimah, O. Al-Otibi: Assessment of antifungal activity of Rumexvesicarius L. and Ziziphusspinachristi (L.) wild extracts against two phytopathogenic fungi. Afr J Microbiol Res. 2011 5(9): 1001-1011.

11. Odebode AC: Control of post harvest pathogens of fruits by culture filtrate from antagonistic fungi. In Journal of Plant Protec Res. 200646 (1): 1-6.

12. Sivasithamparam K and Ghisalberti EL: Secondary metabolism in Trichoderma and Gliocladium. Vol. 1, London. 1998, 139-192.

13. Kucuk C and Kivanc M: Isolation of Trichoderma species and determination of their antifungal, biochemical and physiological features. Turkish Journal of Biology 2003 27: 247-253.

14. Heydari A and Pessarakli M: A Review on Biological Control of Fungal Plant Pathogens Using Microbial Antagonists. Journal of Biological Sciences 2010 10: 273-290.

15. Vinale F, Sivasithamparam K, Ghisalberti LE, Marra R, Woo LS and Lorito M: Trichoderma-plantpathogen interactions. Soil Biol Biochem. 2008 40: 110.

16. Harman GE, Howell CR, Viterbo A, Chet I, and Lorito M: Trichoderma species-opportunistic, a virulent plant symbiont. Nature Rev Microbiol. 2004 2: 43-56.

17. Flegel TW: Semi permanent microscope slides of micro fungi using sticky tape technique, Canadian Journal of Microbiology 1980 26: 551-553.

18. Hajiegharai B, Torabi-giglou M, Mohammadi MR, Davari M: Biological potential of some Iranian Trichoderma isolates in the control of soil born plant pathogenic fungi. African Journal of Biotechnology 2008 7(8): 967-972.

19. Okereke V.C and Wokocha R.C: Effects of Some Tropical Plant Extracts, Trichoderma harzianum and Captan on the Damping-off Disease of Tomato Induced by Sclerotium rolfsii. Agricultural Journal 2006 1: 52-54.

20. Asad SA, Ali N, Hameed A, Khan SA, Ahmad R, Bilal M, Shahzad M and Tabassum A: Biocontrol
Efficacy of Different isolates of Trichoderma against Soil Borne Pathogens Rhizoctonia solani. Polish Journal of Microbiology 2014 1: 95-103.

21. Burgess LW and Griffin DM: Competitive saprophytic colonization of wheat straw. Ann appl Biol. 1967 60: 137-42.

22. Barari H, ForoutanA: Biocontrol of Soybean Charcoal Root Rot Disease by Using Trichoderma spp. Agronomic research in Moldavia 2013 45-55.

23. Dubey SC, Suresh M and Singh B: Evaluation of Trichoderma species against Fusarium oxysporum fsp. Ciceris for integrated management of chickpea wilt. Biol Contr. 2007 40: 118-127.

24. Ponnusamykonar P, Venkitasamy $\mathrm{K}$ and Varatharajan P: In vitro study of antagonistic effect of Trichoderma sp., on tea plant pathogen, Phomopsistheae. Archives of Applied Science Research 2011 3(4):352-358.

25. Behzad H, Mousa T, Mohammad RM, Mahdi D: Biological potential of some Iranian Trichoderma isolates in the control of soil borne plant pathogenic fungi. Afr J Biotechnol. 2008 7: 967-972. 